\title{
Outcomes analysis of an alternative formulation of PEGylated liposomal doxorubicin in recurrent epithelial ovarian carcinoma during the drug shortage era [Corrigendum]
}

\author{
Berger JL, Smith A, Zorn KK, et al. Onco Targets Ther. \\ 2014;7:1409-1413.
}

It has been brought to our attention that there are two pharmaceutical companies that market drugs with the name 'lipodox' and we erroneously refer to the product used in our current study-Outcomes analysis of an alternative formulation of PEGylated liposomal doxorubicin in recurrent epithelial ovarian carcinoma during the drug shortage era. by the trade name Lipo-dox ${ }^{\circledR}$, a drug produced by TTY Biopharm Co. Ltd, when the Sun Pharma product is Lipodox. Lipo-Dox ${ }^{\circledR}$ utilizes a different liposomal particle than Doxil ${ }^{\circledR}$, DSCP versus HSCP. Due to the similarity of the drug names, we were under the mistaken impression that Sun Pharma's Lipodox utilized the DSCP liposome. We postulated that this might be related to the poor clinical outcomes seen in our population. It is now clear that Lipodox utilizes the same liposome as Doxil ${ }^{\circledR}$ and this is not a relevant point of discussion. The authors would like to let the readers know that Lipodox uses HSCP as the liposome and this should be corrected in the manuscript. The patients in our current study were all treated with Lipodox, and this drug uses HSCP as the liposome.

\section{Publish your work in this journal}

OncoTargets and Therapy is an international, peer-reviewed, open access journal focusing on the pathological basis of all cancers, potential targets for therapy and treatment protocols employed to improve the management of cancer patients. The journal also focuses on the impact of management programs and new therapeutic agents and protocols on patient perspectives such as quality of life, adherence and satisfaction. The manuscript management system is completely online and includes a very quick and fair peer-review system, which is all easy to use. Visit http://www.dovepress.com/testimonials.php to read real quotes from published authors. 